\title{
G

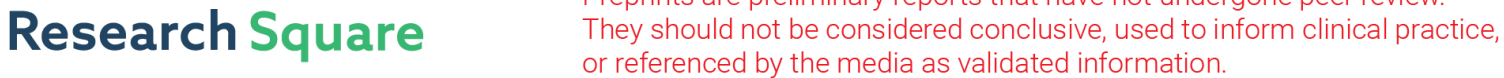

\section{Dominant climate drivers of wintertime severe particulate pollution in North China}

Jiandong Li

Nanjing University of Information Science and Technology https://orcid.org/0000-0002-5857-8177

Xin Hao

Nanjing University of Information Science and Technology

Hong Liao ( $\square$ hongliao@nuist.edu.cn )

Nanjing University of Information Science and Technology https://orcid.org/0000-0001-6628-1798

\section{Yuhang Wang}

Georgia Institute of Technology https://orcid.org/0000-0002-7290-2551

\section{Wenju Cai}

CSIRO Oceans and Atmosphere https://orcid.org/0000-0001-6520-0829

Ke Li

Harvard University https://orcid.org/0000-0002-9181-3562

\section{Xu Yue}

Nanjing University of Information Science and Technology https://orcid.org/0000-0002-8861-8192

\section{Yang Yang}

Nanjing University of Information Science and Technology

\section{Haishan Chen}

Nanjing University of Information Science and Technology https://orcid.org/0000-0002-2403-3187

\section{Yuhao Mao}

Nanjing University of Information Science and Technology

\section{Yu Fu}

Institute of Atmospheric Physics, Chinese Academy of Sciences

\section{Lei Chen}

Nanjing University of Information Science and Technology

Jia Zhu

Nanjing University of Information Science and Technology

\section{Article}

\section{Keywords:}

Posted Date: December 2nd, 2021 
DOI: https://doi.org/10.21203/rs.3.rs-84359/v1

License: (c) (i) This work is licensed under a Creative Commons Attribution 4.0 International License. Read Full License 


\section{Abstract}

Severe particulate pollution days (SPPDs, characterized by a daily mean PM2.5 concentration exceeding $150 \mu \mathrm{g} \mathrm{m}-3$ ), which are extremely harmful to human health and the environment, occurred frequently in North China during the boreal winters of 2013-2019. SPPDs generally occur under conducive weather patterns (CWPs) characterized by a weakened East Asian Trough in the mid-troposphere, reduced winter northerlies in the lower troposphere, and a temperature inversion at the surface. The occurrence of CWPs has been attributed to variations in numerous climate factors (e.g., Arctic sea ice cover, sea surface temperature, and atmospheric teleconnections), but the dominant climate drivers remain inconclusive. Here, we show that the East Atlantic-West Russia (EA/WR) teleconnection pattern and the Victoria Mode (VM) of sea surface temperature anomalies are the first and second dominant climate drivers, respectively, leading to CWPs in North China through the zonal and meridional propagations of Rossby waves and explaining $36.3 \%$ and $18.5 \%$, respectively, of the observed wintertime SPPDs in Beijing-TianjinHebei. Our results suggest that, with the help of seasonal forecast from climate models, the indices of the EA/WR and VM can be used to predict wintertime SPPDs over Beijing-Tianjin-Hebei.

\section{Full Text}

North China, especially the Beijing-Tianjin-Hebei (BTH) region, frequently experiences severe particulate pollution days (SPPDs, days when the daily mean $\mathrm{PM}_{2.5}$ concentration exceeds $150 \mu \mathrm{g} \mathrm{m}^{-3}$ ) in boreal winter (December, January, and February, DJF) ${ }^{1,2}$, which have adverse impacts on visibility ${ }^{3}$, ecosystems ${ }^{4}$, and human health ${ }^{5}$. During January 2013 , the observed $\mathrm{PM}_{2.5}$ concentrations reached as high as $680 \mathrm{\mu g} \mathrm{m}^{-3}$ in Beijing ${ }^{6}$. Although stringent clean air regulations have since been implemented in China and the annual mean $\mathrm{PM}_{2.5}$ concentration in China decreased by approximately 33\% over 2013$2017^{7}$, unexpected SPPDs still occurred in Beijing during the COVID-19 lockdown period (JanuaryFebruary 2020) ${ }^{8,9}$. Therefore, understanding the mechanisms responsible for the occurrence of SPPDs is important for air quality management planning.

While their underlying cause is attributed to high anthropogenic emissions associated with rapid economic development, SPPDs generally occur under conducive weather patterns (CWPs) favorable to the formation and accumulation of pollutants ${ }^{10}$. The atmospheric circulation pattern over North China during haze days was characterized by weakened northerlies and the development of a temperature inversion in the lower troposphere, a weakened East Asian Trough in the mid-troposphere, and a northward shift of the East Asian jet in the upper troposphere ${ }^{11}$. Similar anomalous atmospheric circulation patterns were also reported in other studies ${ }^{1,12}$. These features of CWPs were obtained from the composite analysis of haze days or SPPDs. Nevertheless, CWPs should be further classified to quantify the occurrence frequency of each CWP and to understand how climate drivers help shape different CWPs. 
Previous studies suggested that various climate factors are correlated with variations in haze pollution throughout China on interannual to decadal timescales. For example, the weakening of the East Asian winter monsoon increase the average concentrations of $\mathrm{PM}_{2.5}$ in North China ${ }^{13}$. The reduced autumn Arctic sea ice cover was reported to result in a more stable atmosphere and hence more haze days in the following winter in eastern China ${ }^{14}$. Sea surface temperature anomalies (SSTAs) in the Pacific Ocean ${ }^{12}$, 15,16 , Atlantic Ocean ${ }^{15}$ and Indian Ocean ${ }^{17}$ were found to be linked with variations in haze days. Furthermore, teleconnections, such as the East Atlantic-West Russia (EA/WR) pattern ${ }^{18}$ and the Eurasian pattern ${ }^{19}$, cause the formation of SPPDs by inducing anomalous circulation conditions. CWPs are also projected to increase under future scenarios of climate warming $1,20,21,22$. However, previous studies usually focused on a single climate factor. As such, the climate factors that are predominantly responsible for most SPPDs remain unclear.

Here we show that the EA/WR teleconnection pattern is the dominant climate driver for SPPDs in BTH. We employed $\mathrm{PM}_{2.5}$ observations in BTH during DJF of 2013-2019 from the observational network of the Chinese Ministry of Ecology and Environment (Fig. 1a) and identified the CWPs for SPPDs by using a weather pattern classification approach. We then assigned historical daily DJF circulation patterns during 1979-2019 into CWPs to obtain reconstructed CWPs (R-CWPs). The most dominant climate factor was determined by the highest frequency of R-CWPs caused by that factor.

\section{Typical Cwps For Sppds And Reconstructed Historical Cwps}

To identify CWPs, we selected the key meteorological variables that drive daily variations in $\mathrm{PM}_{2.5}$. Correlations of $\mathrm{PM}_{2.5}$ with various meteorological variables, including geopotential height, temperature, winds, relative humidity, and sea level pressure, were examined during DJF of 2013-2019. High correlations were found with the zonal flow of the upper troposphere at $200 \mathrm{hPa}(\mathrm{U} 200)$, the geopotential heights at $500 \mathrm{hPa}(\mathrm{Z} 500)$ and $850 \mathrm{hPa}$, the meridional flow at $850 \mathrm{hPa}$ (V850), the vertical difference in the temperature anomalies between $850 \mathrm{hPa}$ and $250 \mathrm{hPa}$, and the relative humidity at 1000 hPa (Supplementary Fig. 1). Among these variables, U200, Z500 and V850 were ultimately selected considering that climate factors influence CWPs by changing large-scale circulations. These three parameters have also been reported to be important for the formation of SPPDs 1, 11, 21 . Assuming that the daily concentration of $\mathrm{PM}_{2.5}$ averaged over $\mathrm{BTH}(x)$ is related to the daily meteorological variable $(y)$ at a grid cell following $y=a x+b$ (where $y$ is one of $U 200, Z 500$, and V850), maps of the regression coefficient (a) were utilized to quantify the meteorological changes in response to $\mathrm{PM}_{2.5}$ fluctuations (Supplementary Fig. 2). Then, guided by the highest positive and negative regression coefficients, the meteorological parameters in the black rectangles in Supplementary Figs. 2a-c were used to classify the CWPs.

By using U200, Z500, and V850 identified above, we classified the daily weather conditions during DJF of 2013-2019 (632 days) into 7 types (see Methods, hereafter referred to as T1 through T7) (Supplementary Fig. 3). T1 through T7 accounted for $15.2 \%, 13.0 \%, 20.1 \%, 11.6 \%, 22.6 \%, 7.1 \%$ and $10.4 \%$ of the weather 
conditions among all 632 days. Considering the mean $\mathrm{PM}_{2.5}$ concentration, the mean $\mathrm{PM}_{2.5}$ anomalies, the number of observed SPPDs, and the percentage of SPPDs among that type of wintertime days, the T5

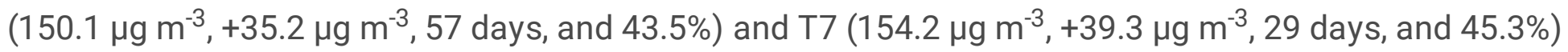
were CWPs that induced the most occurrences of SPPDs, while the T1 $\left(109.5 \mu^{-3} \mathrm{~m}^{-3},-5.3 \mu \mathrm{g} \mathrm{m}^{-3}, 24\right.$ days, and $26.7 \%)$, T2 (105.9 $\mathrm{g} \mathrm{m}^{-3},-9.0 \mu \mathrm{g} \mathrm{m}^{-3}, 16$ days, and $\left.22.2 \%\right)$ and T6 $\left(116.9 \mu \mathrm{g} \mathrm{m}^{-3},+2.0 \mu \mathrm{g} \mathrm{m}^{-3}, 10\right.$ days, and $22.7 \%)$ patterns resulted in moderate pollution, and the T3 $\left(86.0 \mu \mathrm{g} \mathrm{m}^{-3},-28.9 \mu \mathrm{g} \mathrm{m}^{-3}, 14\right.$ days, and $11.4 \%)$ and $\mathrm{T} 4\left(79.6 \mu \mathrm{g} \mathrm{m}^{-3},-35.3 \mu \mathrm{g} \mathrm{m}^{-3}, 7\right.$ days, and $\left.9.7 \%\right)$ patterns corresponded to relatively clean patterns (Fig. 1b and Supplementary Fig. 4). During 2013-2019, there were 157 wintertime SPPDs, of which 86 days (54.8\%) occurred under T5 and T7 weather patterns (Fig. 1a). Note that anthropogenic emissions constituted another important factor for the occurrence of SPPDs. For example, SPPDs did not occur following the Chinese Spring Festival due to relatively low emission levels even though the weather patterns were CWPs.

Multidecadal data are needed to detect the dominant climate factor leading to CWPs since climate represents the long-term average of weather. On the basis of the CWPs (T5 and T7) found above (Figs. 1c-1h), the long-term changes in CWPs were reconstructed by assigning the historical daily DJF weather conditions during 1979-2019 into T5 and T7 by using the smallest Euclidean distance (see Methods). The frequencies of the R-CWPs over 1979-2019 show no significant trends but large interannual variations for T5, T7 and T5+T7 (Fig. 2), which are associated with the variations in climate factors as discussed subsequently. We evaluated the R-CWPs in several ways. For 2013-2019, the R-CWPs agree with the CWPs classified using U200, Z500, and V850 (Fig. 2), with correlation coefficients of 0.97, 0.96 and 0.96 for T5, T7 and T5+T7, respectively. The long-term record of observed $\mathrm{PM}_{2.5}$ from the US Embassy in Beijing over 2009-2019 demonstrates that the interannual variation of observed SPPDs matches that of the T5+T7 R-CWPs. The low frequencies of observed SPPDs at the US Embassy in Beijing over 2017-2019 indicate the result of the Clean Air Action. The variations in CWPs reconstructed using the NCEP1 and NCEP2 reanalysis over 1979-2019 resemble those of R-CWPs reconstructed by ERA5, with high correlation coefficients of 0.93-0.95 (Supplementary Fig. 5). Moreover, the pattern correlations between composite anomalies of the R-CWPs during 1979-2019 and those of CWPs during 2013-2019 are in the range of 0.88 to 0.99 (Supplementary Fig. 6). Considering these evaluations, we leveraged the T5 and T7 R-CWPs in 1979-2019 to identify the dominant climate factors that cause SPPDs.

\section{Dominant Climate Drivers Of Sppds}

We first performed correlation analyses to explore the potential linkage between climate factors and RCWPs. Supplementary Figs. 7-9 show heatmaps of the correlation coefficients between T5/T7 and 85 atmospheric indices (Supplementary Table 1) and 26 SST indices (Supplementary Table 2), respectively. We found that T5 is highly correlated with atmospheric teleconnection indices, such as the East Atlantic pattern , the EA/WR pattern and the Asian Zonal Circulation Index (Supplementary Fig. 7). In contrast, T7 is correlated mainly with the SST of the Pacific Ocean, e.g., the Oyashio Current SST Index, the Kuroshio 
Current SST Index, the West Wind Drift Current SST Index, and the NINO A SST Anomaly (SSTA) Index (Supplementary Fig. 9). Hence, the dominant climate factors linked to SPPDs in BTH are examined based on these two aspects. Other climate factors, including the Arctic sea ice, atmospheric teleconnections, and SST over the Indian and Atlantic Ocean, are excluded as described in details in Supplementary Text1.

Boreal wintertime teleconnections, such as the Pacific/North American pattern, the West Pacific pattern, and the East Atlantic pattern, can be detected from the geopotential height field at $500 \mathrm{hPa} 23,24$. Hence, we used the annual DJF mean $500 \mathrm{hPa}$ geopotential height to regress the T5 R-CWP over the Eurasian continent from 1979 to 2019 (for each grid in the studied domain, the regression coefficient is calculated by a simple linear regression, $y=a x+b$, where T5 is $x$ and the DJF mean $500 \mathrm{hPa}$ geopotential height is $y$, thus, the regression coefficient, $a$, indicates the Z500 anomaly in response to changes in T5). Fig. 3a shows the spatial distribution of the regression coefficient, revealing a planetary-scale stationary wave pattern extending to the North Atlantic Ocean at approximately $45^{\circ} \mathrm{N}$, western Europe, central Russia, and mid-latitude East Asia with alternating positive/negative anomalies. This pattern is similar to the EA/WR pattern, whose impact extends from the North Atlantic to the whole Eurasian mainland 25,26 . Based on these findings, we examined the leading modes of large-scale teleconnections from the DJF mean 500 hPa geopotential height field. The spatial distribution of the second empirical orthogonal function mode (EOF2) eigenvector (Fig. 3b), which represents the EA/WR pattern, displays nearly the same structure as the regression map of the $500 \mathrm{hPa}$ geopotential height on T5. A close correlation is found between T5 and the time series of the corresponding second principal component (PC2, Fig. 3c) with a statistically significant correlation coefficient of 0.76 .

The EA/WR pattern is essentially tied to large-scale stationary waves, which are forced by vorticity transients in the mid-latitude Atlantic or by a diabatic heat source over the subtropical Atlantic near the Caribbean Sea ${ }^{26}$. Horizontal wave activity fluxes (see Methods) at $200 \mathrm{hPa}$ associated with the EA/WR pattern show that a source of the wave train is located over the mid-latitude Atlantic at approximately $40^{\circ} \mathrm{N}$; the wave train propagates eastward and branches at $15^{\circ} \mathrm{W}$ (Fig. $3 \mathrm{e}$ ), whereupon one branch extends to East Asia via western Europe and western Russia, while the other branch propagates southeastward to the Middle East via West Africa (Fig. 3e). Note that the horizontal wave activity fluxes associated with T5 display a clear wave train pattern extending from the mid-latitude North Atlantic to East Asia through western Europe and western Russia, which closely matches the North Atlantic-Eurasian route of Rossby wave propagation associated with the EA/WR pattern (Fig. 3d). As for T5 (Figs. 1c, 1e and $\mathbf{1 g}$ ), the northeastward shifted jet stream acts as a waveguide for Rossby waves, motivating a weak and shallow East Asian Trough to obstruct the southward outbreak of cold air. This suggests that the EA/WR pattern is responsible for T5 CWPs over BTH. Considering that T5 is the most frequent weather pattern (accounting for $22.6 \%$ of wintertime days in 2013-2019, 21.6\% of wintertime days in 1979-2019, and $36.3 \%$ of the observed SPPDs in 2013-2019), the EA/WR pattern is identified as the dominant climate factor that leads to SPPDs in BTH. 
The reconstructed time series of T7 display a statistically significant relationship with the SSTAs in the North Pacific Ocean. As shown in Fig. 4a, the linear coefficients of SST regressed on the T7 R-CWPs time series exhibit a northeast-southwest-oriented dipole pattern in the North Pacific poleward of $20^{\circ} \mathrm{N}$; this pattern is characterized by a band of positive anomalies extending from the western coast of North America across the Pacific to the western Bering Sea and a band of negative anomalies extending from the coast of Asia to the central North Pacific. Weak positive correlations were also found in the tropical central North Pacific (Fig. 4a). When these features are considered together, the regression map seems to display a Victoria Mode (VM) SSTA ${ }^{27}$. Fig. 4 b shows the VM, which is defined as the EOF2 of the SSTAs in the North Pacific poleward of $20^{\circ} \mathrm{N}^{27,28}$. The spatial distribution of the VM resembles the SSTA pattern associated with T7, and the correlation coefficient between the two time series is 0.65 (Fig. 4c).

Previous studies indicated that the VM pattern imparted from the North Pacific Oscillation can induce overlaying atmospheric anomalies, leading to an anomalous wintertime zonal wind stress over the North Pacific ${ }^{28,29}$. Fig. 4 e shows the wave activity flux and stream function regressed on the normalized VM index at $200 \mathrm{hPa}$, illustrating that a Rossby wave train originates from the western North Pacific likely induced by heat flux anomalies associated with western-boundary currents and propagates northward to northern East Asia and then eastward to the high-latitude North Pacific. This corresponding Rossby wave train provides a connection between the VM and East Asian regional circulation. The Rossby wave associated with the T7 R-CWP displays a similar propagation pattern (Fig. 4d) to East Asia along the weakened and southward-shifted jet stream, leading to a weakened East Asian Trough and stable weather conditions (Figs. 1d and 1f). Consequently, northwesterly winds are impaired, and thus, they transport less cold and dry air to BTH during winter (Fig. 1h). The overall similarities between the T7 RCWP and VM imply a dynamic link between the VM and SPPDs in BTH. It should be noted that the meridional dipolar anomaly over East Asia can also be partly influenced by internal variability of Western Pacific teleconnection ${ }^{30}$. Compared to T5, T7 has a lower frequency of occurrence, accounting for $10.4 \%$ of wintertime days in $2013-2019,10.6 \%$ wintertime days in $1979-2019$, and $18.5 \%$ of the observed SPPDs in 2013-2019.

\section{Prediction Ability Of The Dominant Climate Drivers}

Since there is no linearity relationship between time series of the EA/WR and VM $(R=0.12)$, they can be used to predict the frequency of CWPs in BTH. A statistical scheme is established using the multi-linear regression method, $y=a x_{1}+b x_{2}+c$, in which two predictors $\left(x_{1}\right.$ and $\left.x_{2}\right)$ denote the EA/WR and VM, while $y$ denotes the predicted (observed) frequency of CWPs for T5+T7, with $a / b$ and $c$ being regression coefficients and intercept. Both cross-validation and independent hindcast were carried out to verify the capability of predicting CWPs. For cross-validation, a one-year-out-cross-validation approach was used, with any individual year out of 1979-2019 being the target year and the multi-linear regression established for the remaining 40 years. As for independent hindcasts, period of 1979-2012 was used for training and another period of 2013-2019 was used for the evaluation of prediction. Fig. 5a shows the 
1979-2019 cross-validation test. The correlation coefficient, root mean square error and percentage of the same mathematical sign in Fig. $5 \mathbf{a}$ is $0.68,7.68$ days, and $80.5 \%$ (33/41), respectively, indicating a proper stability of our prediction model. In Fig. $\mathbf{5 b}$ the predicted CWPs by independent hindcast can successfully reproduce the interannual variability of observed CWPs in 2013-2019. The over-all period for 1979-2019 predictions have a significant correlation with observations, with correlation coefficient and root mean square error being 0.73 and 7.24 days (Fig. 5c), respectively. Therefore, we conclude that, with the help of seasonal forecast from climate models (see Supplementary Text2), the EA/WR and VM can be used to predict the future wintertime frequency of CWPs in BTH.

In summary, in this study, we identified the dominant climate factors that cause wintertime SPPDs in BTH. The EA/WR teleconnection pattern was found to be the dominant climate factor (inducing $36.3 \%$ of the observed SPPDs over 2013-2019) that results in CWPs for SPPDs in North China through the propagation of large-scale stationary waves originating from the mid- to high latitudes of the North Atlantic to East Asia via western Europe and western Russia. The VM SSTAs in the North Pacific Ocean were found to be the second predominant climate factor (inducing $18.5 \%$ of the observed SPPDs over 2013-2019) leading to SPPDs in North China by a wave train extending from the western North Pacific to the high-latitude North Pacific. The indices of the EA/WR and VM (Figs. 3c and 4c) can be used to predict wintertime SPPDs over BTH, offering guidance for emission reduction strategy.

\section{References}

1. Cai W, Li K, Liao H, Wang H, Wu L. Weather conditions conducive to Beijing severe haze more frequent under climate change. Nat Clim Change 2017, 7(4): 257-262.

2. Li J, Liao H, Hu J, Li N. Severe particulate pollution days in China during 2013-2018 and the associated typical weather patterns in Beijing-Tianjin-Hebei and the Yangtze River Delta regions. Environ Pollut 2019, 248: 74-81.

3. Yang Y, Liao H, Lou S. Increase in winter haze over eastern China in recent decades: Roles of variations in meteorological parameters and anthropogenic emissions. J Geophys Res Atmos 2016, 121(21): 13,050 - 013,065.

4. Yue $\mathrm{X}$, Unger $\mathrm{N}$, Harper $\mathrm{K}$, Xia $\mathrm{X}$, Liao $\mathrm{H}$, Zhu T, et al. Ozone and haze pollution weakens net primary productivity in China. Atmos Chem Phys 2017, 17(9): 6073-6089.

5. Hu J, Huang L, Chen M, Liao H, Zhang H, Wang S, et al. Premature Mortality Attributable to Particulate Matter in China: Source Contributions and Responses to Reductions. Environ Sci Technol 2017, 51(17): 9950-9959.

6. Wang Y, Yao L, Wang L, Liu Z, Ji D, Tang G, et al. Mechanism for the formation of the January 2013 heavy haze pollution episode over central and eastern China. Sci China Earth Sci 2014, 57(1): 14-25.

7. Zhang $\mathrm{Q}$, Zheng $\mathrm{Y}$, Tong $\mathrm{D}$, Shao $\mathrm{M}$, Wang $\mathrm{S}$, Zhang $\mathrm{Y}$, et al. Drivers of improved PM2.5 air quality in China from 2013 to 2017. Proc Nat Acad Sci USA 2019, 116(49): 24463-24469. 
8. Huang X, Ding A, Gao J, Zheng B, Zhou D, Qi X, et al. Enhanced secondary pollution offset reduction of primary emissions during COVID-19 lockdown in China. Natl Sci Rev 2020.

9. Wang P, Chen K, Zhu S, Wang P, Zhang H. Severe air pollution events not avoided by reduced anthropogenic activities during COVID-19 outbreak. Resour Conserv Recyc/2020, 158.

10. Zhao XJ, Zhao PS, Xu J, Meng W, Pu WW, Dong F, et al. Analysis of a winter regional haze event and its formation mechanism in the North China Plain. Atmos Chem Phys 2013, 13(11): 5685-5696.

11. Chen $\mathrm{H}$, Wang $\mathrm{H}$. Haze Days in North China and the associated atmospheric circulations based on daily visibility data from 1960 to 2012. J Geophys Res Atmos 2015, 120(12): 5895-5909.

12. Pei L, Yan Z, Sun Z, Miao S, Yao Y. Increasing persistent haze in Beijing: potential impacts of weakening East Asian winter monsoons associated with northwestern Pacific sea surface temperature trends. Atmos Chem Phys 2018, 18(5): 3173-3183.

13. Zhao S, Feng T, Tie X, Li G, Cao J. Air Pollution Zone Migrates South Driven by East Asian Winter Monsoon and Climate Change. Geophys Res Lett 2021, 48(10): e2021GL092672.

14. Wang $\mathrm{H}$, Chen $\mathrm{H}$, Liu J. Arctic Sea Ice Decline Intensified Haze Pollution in Eastern China. Atmos Ocean Sci Lett 2015, 8(1): 1-9.

15. Wang J, Zhu Z, Qi L, Zhao Q, He J, Wang JXL. Two pathways of how remote SST anomalies drive the interannual variability of autumnal haze days in the Beijing-Tianjin-Hebei region, China. Atmos Chem Phys 2019, 19(3): 1521-1535.

16. Yin $Z$, Wang $H$. The relationship between the subtropical Western Pacific SST and haze over NorthCentral North China Plain. Int J Climatol 2016, 36(10): 3479-3491.

17. Shen L, Jacob DJ, Mickley LJ, Wang Y, Zhang Q. Insignificant effect of climate change on winter haze pollution in Beijing. Atmos Chem Phys 2018, 18(23): 17489-17496.

18. Yin Z, Wang H. Role of atmospheric circulations in haze pollution in December 2016. Atmos Chem Phys 2017, 17(18): 11673-11681.

19. Zou Y, Wang Y, Xie Z, Wang H, Rasch PJ. Atmospheric teleconnection processes linking winter air stagnation and haze extremes in China with regional Arctic sea ice decline. Atmos Chem Phys 2020, 20(8): 4999-5017.

20. Zou Y, Wang Y, Zhang Y, Koo JH. Arctic sea ice, Eurasia snow, and extreme winter haze in China. Sci Adv 2017, 3(3): e1602751.

21. Pei L, Yan Z. Diminishing clear winter skies in Beijing towards a possible future. Environ Res Lett 2018, 13(12): 124029.

22. Chen $\mathrm{H}$, Wang $\mathrm{H}$, Sun $\mathrm{J}, \mathrm{Xu} Y$, Yin Z. Anthropogenic fine particulate matter pollution will be exacerbated in eastern China due to 21st century GHG warming. Atmos Chem Phys 2019, 19(1): 233-243.

23. Wallace JM, Gutzler DS. Teleconnections in the Geopotential Height Field during the Northern Hemisphere Winter. Mon Weather Rev 1981, 109(4): 784-812. 
24. Horel JD, Wallace JM. Planetary-Scale Atmospheric Phenomena Associated with the Southern Oscillation. Mon Weather Rev 1981, 109(4): 813-829.

25. Krichak SO, Breitgand JS, Gualdi S, Feldstein SB. Teleconnection-extreme precipitation relationships over the Mediterranean region. Theor App/ Climatol 2013, 117(3-4): 679-692.

26. Lim Y-K. The East Atlantic/West Russia (EA/WR) teleconnection in the North Atlantic: climate impact and relation to Rossby wave propagation. Clim Dyn 2014, 44(11-12): 3211-3222.

27. Bond NA, Overland JE, Spillane M, Stabeno P. Recent shifts in the state of the North Pacific. Geophys Res Lett 2003, 30(23).

28. Ding R, Li J, Tseng Y-h, Sun C, Guo Y. The Victoria mode in the North Pacific linking extratropical sea level pressure variations to ENSO. J Geophys Res Atmos 2015, 120(1): 27-45.

29. Ding R, Li J, Tseng Y-h, Sun C, Zheng F. Linking a sea level pressure anomaly dipole over North America to the central Pacific El Niño. Clim Dyn 2017, 49(4): 1321-1339.

30. Tanaka S, Nishii K, Nakamura H. Vertical Structure and Energetics of the Western Pacific Teleconnection Pattern. J Clim 2016, 29(18): 6597-6616.

\section{Declarations}

Correspondence and requests for materials should be addressed to Hong Liao (hongliao@nuist.edu.cn)

\section{Acknowledgments}

This work was supported by the National Natural Science Foundation of China (grant nos. 91744311, 41421004 and 42088101) and by the Major Research Plan of the National Social Science Foundation (grant no. 18ZDA052).

\section{Author contributions}

J.L., X.H., and H.L. conceived the study. J.L. and X.H. performed the data analysis. Y.W and W.C. contributed to interpreting the scientific questions. J.L., X.H. and H.L. wrote the draft of the manuscript. All authors contributed to discussing and improving the manuscript.

\section{Competing interests}

The authors declare no competing interests.

\section{Data And Methods}

\section{Observation data}

The $\mathrm{PM}_{2.5}$ data from December 2013 to February 2020 used in this study are obtained from the Chinese Ministry of Ecology and Environment website (http://106.37.208.233:20035/). A longer record of $\mathrm{PM}_{2.5}$ dataset over 2009-2020 from US Embassy in Beijing is also used 
(https://www.airnow.gov/international/us-embassies-and-consulates/\#China\$Beijing). This dataset has been widely used in previous studies and is reported to well represent $\mathrm{PM}_{2.5}$ variation in $\mathrm{BTH}{ }^{1}, 22,31,32,33$. The daily average $\mathrm{PM}_{2.5}$ is processed and quality controlled following a previous study ${ }^{2}$. The cities with continuous $\mathrm{PM}_{2.5}$ observations since 2013 are displayed in Supplementary Fig. 1a. Daily meteorology fields, including geopotential heights and winds at different pressure levels and mean sea level pressure, are from the fifth-generation reanalysis from the European Centre for Medium-Range Weather Forecasts (ERA5) with a resolution of $2.5^{\circ} \times 2.5^{\circ}$ downloaded from the Copernicus Climate Change Service (C3S, 2017).

The observed sea surface temperatures (SSTs) from the Hadley Centre are downloaded from https://www.metoffice.gov.uk/hadobs/hadisst/ ${ }^{34}$. The anomaly of a parameter on a specific day is calculated relative to the daily climatology spanning 40 years (1979-2018). The EA/WR pattern is defined as the second leading rotated empirical orthogonal function mode of the $500 \mathrm{hPa}$ geopotential height in the region $15^{\circ}-85^{\circ} \mathrm{N}, 70^{\circ} \mathrm{W}-140^{\circ} \mathrm{E}{ }^{23,35}$, and its climate impact extends from eastern North America to Eurasia through wave train propagation. The Victoria Mode is defined as the second leading mode of the SST in the North Pacific Ocean $\left(20^{\circ}-61^{\circ} \mathrm{N}, 100^{\circ} \mathrm{E}-80^{\circ} \mathrm{W}\right)$.

\section{Classification of weather patterns during SPPDs}

We identify the typical weather patterns during DJF during 2013-2019 by using obliquely rotated principal component analysis in T-mode (T-PCA), which is commonly used to classify circulation patterns ${ }^{36}$. This method has also been employed to investigate the circulation patterns that are conducive to particulate pollution in North China ${ }^{2,37}$ and the Yangtze River Delta ${ }^{38}$. In this study, we use the T-PCA method in the Cost733class software package (http://cost733.met.no) to identify typical circulation patterns during DJF in BTH from 2013 to 2019. More details of the T-PCA procedure in cost733class can be found in the literatures ${ }^{2,39}$. The key input meteorological parameters for the classification of weather patterns are identified by linear regression analyses between daily mean meteorological variables and the daily average $\mathrm{PM}_{2.5}$ concentrations of the 10 cities. Three key meteorological parameters are identified: U200, Z500 and V850. We also test other associated variables reported by previous studies. As shown in Supplementary Fig. 2, the regression coefficients of the temperature inversion display nearly the same pattern as those of Z500 (Supplementary Fig. 2b). The regions with maximum variability of the near-surface relative humidity (RH1000, Supplementary Fig. 2d) are too regional compared to U200, Z500 and V850, leading to little influence on the classification results.

The classification performance is evaluated by the explained variation and pseudo- $F$ values (Supplementary Fig. 4a). Seven weather patterns are classified, among which two conducive weather pattern types are identified. Although six classifications results in better performance from a meteorological perspective, seven types can better distinguish the CWPs (Supplementary Figs. 4be). After selecting the appropriate classification, historical daily DJF weather samples from 1979 to 2019 
are assigned to the corresponding CWPs with the smallest Euclidean distance, which is also performed in the cost733class software ${ }^{40}$.

\section{Wave activity fluxes}

The dynamic mechanism by which a climate factor (or pattern) leads to CWPs for the formation of SPPDs is usually a teleconnection, which can be measured by wave activities ${ }^{41}$. In this study, the horizontal wave train flux ${ }^{42}$ is calculated by using meteorological variables (e.g., geopotential height, air density, and pressure level) to display the stream function (wave energy pattern) and intensity and direction of wave propagation. Based on the horizontal wave train flux, we can diagnose the source and propagation direction of stationary waves that lead to CWPs for the formation of SPPDs. This approach has been widely used to examine the relationship between climate factors and circulation patterns for haze pollution in China ${ }^{14,15,18}$.

\section{Data availability}

The surface $\mathrm{PM}_{2.5}$ observations from the Chinese Ministry of Ecology and Environment can be obtained from http://106.37.208.233:20035/ and https://quotsoft.net/air/. The surface $\mathrm{PM}_{2.5}$ observations for US Embassy in Beijing is download from https://www.airnow.gov/international/us-embassies-andconsulates/\#China\$Beijing. The ERA5 reanalysis data is available from https://cds.climate.copernicus.eu/cdsapp\#!/dataset/reanalysis-era5-pressure-levels?tab=form. The observed sea surface temperatures from the Hadley Centre are downloaded from https://www.metoffice.gov.uk/hadobs/hadisst/data/download.html.

\section{Code availability}

The Cost733class software is open source (http://cost733.met.no/).

\section{References}

1. Cai W, Li K, Liao H, Wang H, Wu L. Weather conditions conducive to Beijing severe haze more frequent under climate change. Nat Clim Change 2017, 7(4): 257-262.

2. Li J, Liao H, Hu J, Li N. Severe particulate pollution days in China during 2013-2018 and the associated typical weather patterns in Beijing-Tianjin-Hebei and the Yangtze River Delta regions. Environ Pollut 2019, 248: 74-81.

14. Wang H, Chen H, Liu J. Arctic Sea Ice Decline Intensified Haze Pollution in Eastern China. Atmos Ocean Sci Lett 2015, 8(1): 1-9. 
15. Wang J, Zhu Z, Qi L, Zhao Q, He J, Wang JXL. Two pathways of how remote SST anomalies drive the interannual variability of autumnal haze days in the Beijing-Tianjin-Hebei region, China. Atmos Chem Phys 2019, 19(3): 1521-1535.

18. Yin Z, Wang H. Role of atmospheric circulations in haze pollution in December 2016. Atmos Chem Phys 2017, 17(18): 11673-11681.

22. Chen $\mathrm{H}$, Wang $\mathrm{H}$, Sun J, Xu Y, Yin Z. Anthropogenic fine particulate matter pollution will be exacerbated in eastern China due to 21 st century GHG warming. Atmos Chem Phys 2019, 19(1):233-243.

23. Wallace JM, Gutzler DS. Teleconnections in the Geopotential Height Field during the Northern Hemisphere Winter. Mon Weather Rev 1981, 109(4): 784-812.

31. Shen G, Ru M, Du W, Zhu X, Zhong Q, Chen Y, et al. Impacts of air pollutants from rural Chinese households under the rapid residential energy transition. Nat Commun 2019, 10(1):3405.

32. Dang R, Liao H. Severe winter haze days in the Beijing-Tianjin-Hebei region from 1985 to 2017 and the roles of anthropogenic emissions and meteorology. Atmos Chem Phys 2019, 19(16): 1080110816.

33. Zhang $\mathrm{Y}$, Yin $\mathrm{Z}$, Wang $\mathrm{H}$. Roles of climate variability on the rapid increases of early winter haze pollution in North China after 2010. Atmos Chem Phys 2020, 20(20):12211-12221.

34. Rayner NA. Global analyses of sea surface temperature, sea ice, and night marine air temperature since the late nineteenth century. J Geophys Res 2003, 108(D14).

35. Barnston AG, Livezey RE. Classification, Seasonality and Persistence of Low-Frequency Atmospheric Circulation Patterns. Mon Weather Rev 1987, 115(6): 1083-1126.

36. Huth R, Beck C, Philipp A, Demuzere M, Ustrnul Z, Cahynova M, et al. Classifications of atmospheric circulation patterns: recent advances and applications. Ann NY Acad Sci 2008, 1146: 105152.

37. Zhang JP, Zhu T, Zhang QH, Li CC, Shu HL, Ying Y, et al. The impact of circulation patterns on regional transport pathways and air quality over Beijing and its surroundings. Atmos Chem Phys 2012, 12(11): 5031-5053.

38. Xu J, Chang L, Qu Y, Yan F, Wang F, Fu Q. The meteorological modulation on PM2.5 interannual oscillation during 2013 to 2015 in Shanghai, China. Sci Total Environ 2016, 572: 1138-1149.

39. Philipp A, Bartholy J, Beck C, Erpicum M, Esteban P, Fettweis X, et al. Cost733cat - A database of weather and circulation type classifications. Phys Chem Earth Part A/B/C 2010, 35(9-12): 360-373. 
40. Murawski A, Bürger G, Vorogushyn S, Merz B. Can local climate variability be explained by weather patterns? A multi-station evaluation for the Rhine basin. Hydrol Earth Syst Sci 2016, 20(10): 4283-4306.

41. Boers N, Goswami B, Rheinwalt A, Bookhagen B, Hoskins B, Kurths J. Complex networks reveal global pattern of extreme-rainfall teleconnections. Nature 2019, 566(7744): 373-377.

42. Plumb RA. On the Three-Dimensional Propagation of Stationary Waves. J Atmos Sci 1985, 42(3): 217-229.

\section{Figures}

\section{Figure 1}

Conducive weather patterns favorable for formation of SPPDs. a, Time series of the daily average PM2.5 over BTH during DJF in 2013-2019 (black line). The red dashed line is the $150 \mu \mathrm{g} \mathrm{m}-3$ threshold used to define SPPDs. The highlighted pink rectangles represent the occurrences of T5+T7 weather patterns for the identified CWPs. b, Mean anomalies of PM2.5 relative to the mean of 2013-2019 for each weather type, and the error bars are computed based on a normal distribution 95\% confidence interval. T5 and T7 are identified as CWPs because of their high positive anomalies. $c-h$, Composited anomalous weather patterns of (c, d) U200 (units: $m$ s-1), (e, f) Z500 (units: m2 s-2), ( $g, h$ ) and V850 (units: m s-1) for T5 and T7 over the years of 2013-2019. The inset text in $c$ and $d$ are the frequency of occurrences for T5 and T7 during DJF in 2013-2019. The grey contours in $c$ and $d$ are the western jet streams calculated by DJF means of U200 from 1979 to 2018. T5 display a northeastward shift of jet stream (c) and a weak and shallow East Asian trough (e). T7 is associated with a weakened and southward shift of jet stream (d), accompanied by a weakened East Asian trough (f). Both T5 and T7 show that positive meridional wind anomalies ( $\mathrm{g}-\mathrm{h}$ ) over BTH reduce the prevailing northwesterly winds to bring less cold and dry air to BTH during winter. 

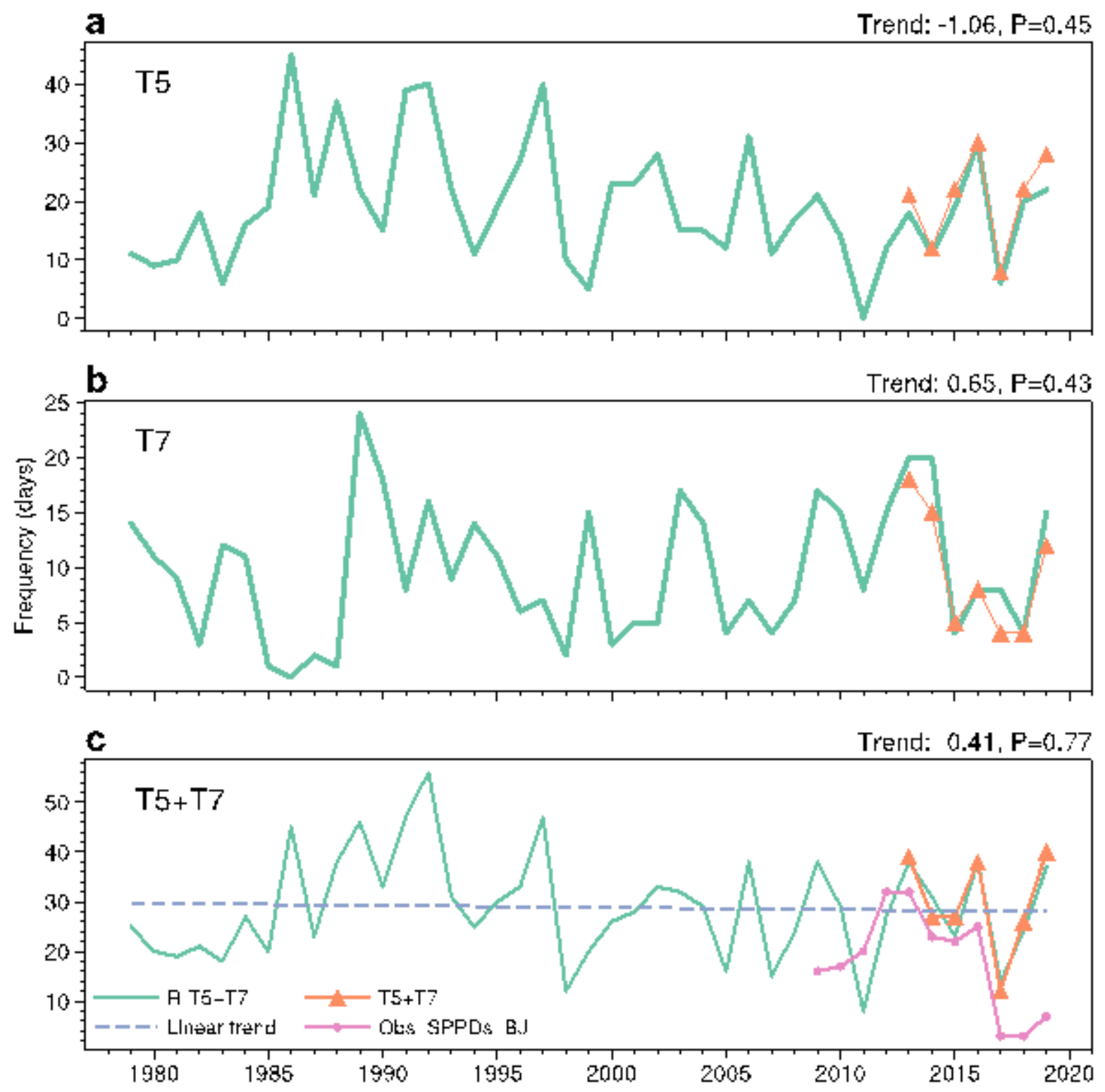

Figure 2

Time series of CWPs and R-CWPs. The green lines and orange lines with triangle markers are reconstructed (1979-2019) and classified (2013-2019) occurrence frequencies in winter for (a) T5, (b) T7 and (c) T5+T7. The pink line in $\mathrm{c}$ is the observed time series of calculated SPPDs obtained from the US Embassy in Beijing over 2009-2020. The inset text "Trend" represents the linear trend calculated by simple linear regression, and " $\mathrm{P}$ " indicates its significance by t-test. R-CWPs in 2013-2019 is consistent with classified CWPs. The frequency of T5+T7 R-CWPs in 2009-2019 can well capture the interannual variations of observed SPPDs in Beijing. The long-term time series of R-CWPs by using multiple reanalysis datasets (see Supplementary Fig. 5) are well matched with each other for the period of 19792019. These evaluations indicate the R-CWPs can be used to investigate underlying climate factors inducing SPPDs. 


\section{Figure 3}

Possible mechanism for T5. a, Linear regression of the $500 \mathrm{hPa}$ geopotential height (unit: $\mathrm{m} 2 \mathrm{~s}-2$ ) with respect to the detrended time series of T5 during DJF for the period 1979-2019. Stippled regions in a indicate that the regression coefficients are statistically significant at the $95 \%$ confidence level based on the Student's t-test. b-c, Spatial pattern of REOF2 of the $500 \mathrm{hPa}$ geopotential height in winter (b) and the associated PC2 (histogram) and frequency of T5 (black dotted line) (c). d-e, The 200 hPa wave activity flux (vector, only values passing the 95\% significance level are shown; units: 10-3 m2s-2 in d and 10-2 m2s-2 in e) and stream function (contour line; units: 104 m2s-1 in d and 105 m2s-1 in e) regressed on the detrended time series of T5 (d) and PC2 (e). Shades area in d-e denotes significant values of regression coefficient of stream function at 90\% (light), 95\% (middle) and 99\% (dark) confidence levels.

\section{Figure 4}

Possible mechanism for T7. a, SST (unit: ${ }^{\circ} \mathrm{C}$ ) regressed on the detrended time series of T7. Stippled regions in a indicate that the regression coefficients are statistically significant at the $95 \%$ confidence level based on the Student's t-test. b, EOF2 of the SSTAs in the North Pacific poleward of $20^{\circ} \mathrm{N}$. c, PC2 of the VM (histogram) and frequency of T7 (black dotted line) for the period 1979-2019. d-e, The $200 \mathrm{hPa}$ wave activity flux (vector; units: 10-2 m2s-2 in d and 10-2 m2s-2 in e) and stream function (contour line; units: $104 \mathrm{~m} 2 \mathrm{~s}-1$ in d and $105 \mathrm{~m} 2 \mathrm{~s}-1$ in e) regressed on the detrended seasonal time series of T7 (d) and PC2 (e) in DJF for the period 1979-2019. Shades area in d-e denotes significant values of regression coefficient of stream function at 90\% (light), 95\% (middle) and 99\% (dark) confidence levels. 

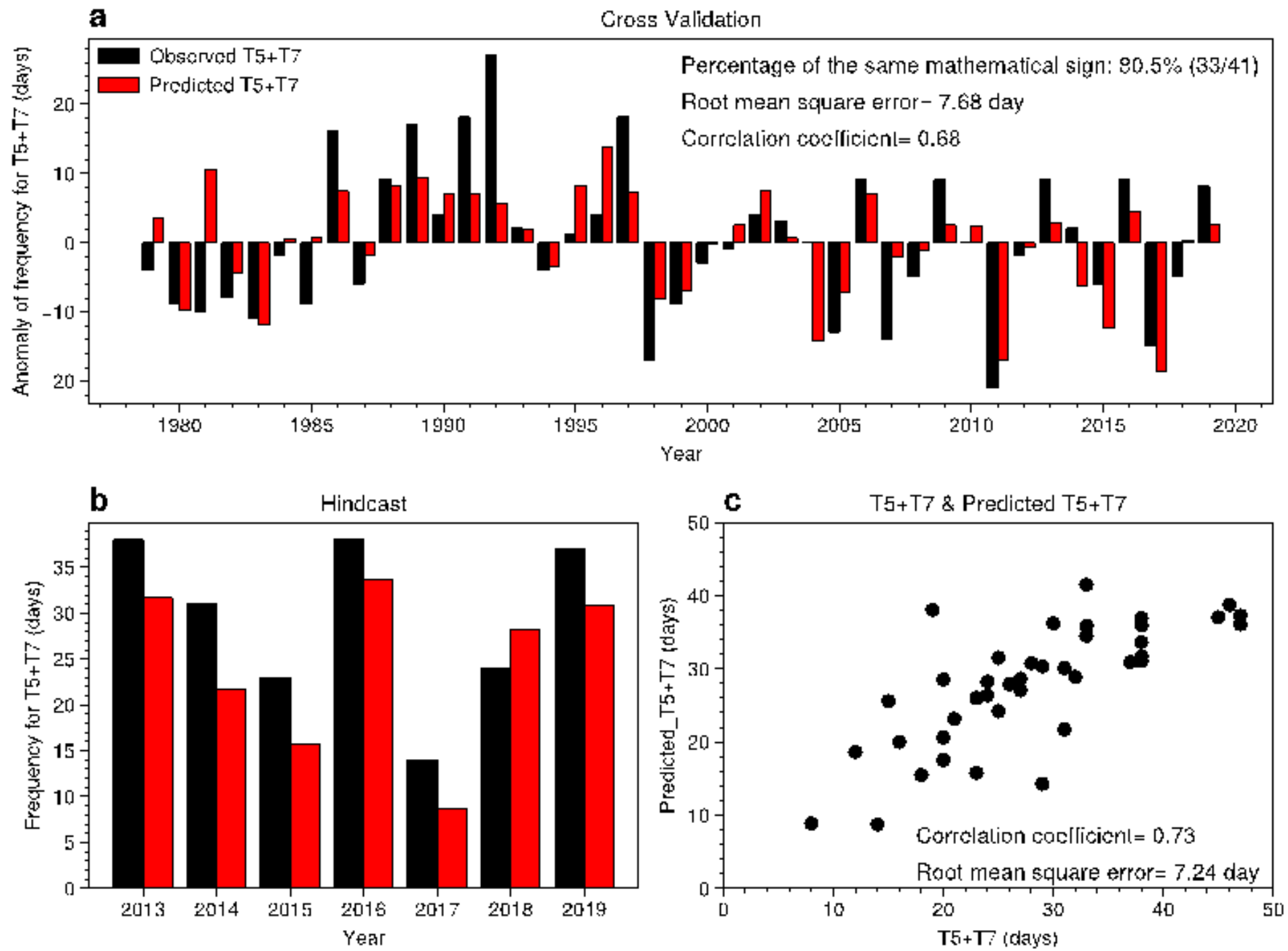

Figure 5

Evaluation of the ability to predict CWPs by EA/WR and VM. a, Verification for the cross-validation test during 1979-2019. Predicted CWPs of each target year was calculated by an empirical prediction model established with the remaining 40 year data. Anomalies with respect to 1979-2019 means for predicted (red histogram) and observed (black histogram) CWPs are shown. b, Performance of independent hindcasts. The period of 1979-2012 was used for training empirical prediction model. CWPs in each year of 2013-2019 was predicted (red histogram) and compared with the observed CWPS (black histogram) of 2013-2019. c, Scatter plot of predicted frequency for T5+T7 CWPs by empirical prediction model trained spanning historical period of 1979-2019 and observed frequency for T5+T7 CWPs in Fig. 2c.

\section{Supplementary Files}

This is a list of supplementary files associated with this preprint. Click to download.

- SubManuscriptNGSupplementaryrevise2.docx 